\title{
Formas de Construtivismo: \\ Mudança Conceitual e Construtivismo Contextual ${ }^{\star}$ \\ Forms of Constructivismo: \\ Conceptual Change and Contextual Constructivism
}

\author{
Charbel Niño El-Hani $^{a}$ e Nelio Marco Vincenzo Bizzo ${ }^{b}$
}

\section{Resumo:}

Geelan (1997), em seu modelo bidimensional das formas de construtivismo, situa o construtivismo contextual, proposto por William Cobern, numa posição diametralmente oposta à pedagogia da mudança conceitual, por ele associada ao construtivismo pessoal. Neste artigo, discutimos as relações entre essas duas formas de construtivismo e algumas implicações para o ensino de Ciências.

Palavras-chave: construtivismo, mudança conceitual, construtivismo contextual, ensino de ciências

\section{Abstract:}

In Geelan's (1997) two-dimensional model of forms of constructivism, William Cobern's contextual constructivism is opposed to conceptual change pedagogy, which Geelan associates with personal constructivism. In this paper, we discuss the relationships between these two forms of constructivism, highlighting some consequences to science teaching.

Key words: constructivism, conceptual change, contextual constructivism, science teaching

\section{Formas de Construtivismo}

\footnotetext{
* Este artigo é uma versão significativamente modificada de trabalho que se encontra nas Atas do II Encontro de Pesquisa em Educação em Ciências (ENPEC), realizado em Valinhos-SP, no mês de Setembro de 1999.

a Grupo de Pesquisa em História, Filosofia e Ensino de Ciências Biológicas, Instituto de Biologia, UFBa. Mestrado em Ensino, Filosofia e História das Ciências, UFBa-UEFS. Mestrado em Ecologia e Biomonitoramento, UFBa. Apoio: CAPES. Bolsista de Produtividade do CNPq/MCT. e-mail: charbel@ufba.br b Departamento de Metodologia de Ensino e Educação Comparada (EDM) da Faculdade de Educação, USP. Bolsista de Produtividade do CNPq/MCT.e-mail: bizzo@usp.br
} 
Este artigo procura discutir a diversidade de formas de construtivismo, enfocando de maneira particular as tensões entre mudança conceitual e construtivismo contextual. Não pretendemos, decerto, esgotar o tema, o qual, em vista da diversidade das concepções construtivistas, requer abordagens de escopo mais amplo do que aquele assumido neste trabalho. Nossos objetivos são, sobretudo, discutir as duas formas de construtivismo mencionadas acima e demonstrar como uma análise mais aprofundada do 'construtivismo' traz à tona a percepção de que esse termo não designa uma tendência unificada de pensamento sobre a aprendizagem, ocultando uma variedade de abordagens e visões diferenciadas que frequentemente é obscurecida pela mera referência àquele rótulo.

Admite-se que o construtivismo pode ser dividido em três correntes: construtivismo educacional; filosófico; e sociológico (Matthews 1997). Não obstante esta divisão, não se pode perder de vista que o construtivismo educacional ou pedagógico apresenta, por certo, aspectos filosóficos e sociológicos, lado a lado com proposições sobre o ensino e a aprendizagem. Em termos epistemológicos, pode-se reconhecer no construtivismo duas teses centrais (Matthews 1994a:82):

(i) O conhecimento é uma construção do sujeito, e não algo que ele possa receber passivamente do meio;

(ii) $O$ ato de conhecer é um processo de adaptação, que organiza o mundo das experiências, mas não conduz à descoberta de uma realidade dada, independente da mente que a conhece.

Estas teses devem ser interpretadas com cautela, visto que se referem a uma das polêmicas mais árduas na epistemologia e filosofia da ciência, concernente à relação entre conhecimento e realidade. A idéia de que o conhecimento é uma construção ativa do sujeito atravessa e constitui toda a epistemologia moderna, mas tem levado, por vezes, a posições controversas como o solipsismo, o subjetivismo e o ceticismo. O solipsismo é usualmente entendido como a tese de que a existência se limita ao sujeito cognoscente. Todo o resto (seres humanos e coisas) seriam idéias desse sujeito. Uma versão mais radical é a de que o único conhecimento epistemologicamente garantido é o conhecimento da experiência imediata do sujeito, das próprias sensações e do 'eu', e que conhecimento comparável de itens 'públicos' não pode ser alcançado. O solipsismo pode ser entendido como uma radicalização extrema do subjetivismo. Por subjetivismo, entende-se a tese de que um dado tipo de juízo é subjetivo. No caso de uma proposição subjetiva, sua verdade ou falsidade não é independente do que os sujeitos pensam ou sentem acerca do assunto em pauta, podendo-se, inclusive, argumentar que não há como afirmar que a proposição seja de fato verdadeira ou falsa. Por exemplo, uma teoria subjetivista da estética ou da moralidade sustenta que os juízos nesses domínios são subjetivos no sentido descrito acima. $O$ ceticismo filosófico, por sua vez, coloca em questão nossas realizações cognitivas, desafiando nossa capacidade de obter conhecimento confiável. O ceticismo pode ter uma natureza global, desafiando todas as nossas tentativas de buscar a verdade, ou restrita, questionando nosso conhecimento de questões éticas, do passado, de outras mentes etc. Desde Descartes, a defesa do conhecimento face ao ceticismo tem sido uma das principais tarefas da epistemologia (ver Honderich 1995). 
A perspectiva construtivista na teoria do conhecimento não tem, contudo, o solipsismo, o ceticismo ou o subjetivismo como decorrências necessárias. É preciso qualificar claramente o que se pretende afirmar, ao assumir-se teses construtivistas como as apresentadas acima. Para compreender-se adequadamente a crítica dirigida, de uma perspectiva construtivista, a uma forma ingênua de realismo, de acordo com a qual não há qualquer distinção entre o mundo como ele é e o mundo como ele se manifesta em seus efeitos sobre os objetos sensíveis - isto é, o mundo seria exatamente como ele é percebido por nós e detectado por nossos instrumentos (cf. Harré 1992:18-23) -, é importante superar qualquer oposição simplória entre realismo e anti-realismo. Criticar uma doutrina realista demasiadamente forte não implica assumir uma posição anti-realista. Deve-se ter na devida conta, por exemplo, que a suposição de que há um mundo exterior independente da mente humana pode afigurar-se inteiramente razoável de uma perspectiva construtivista. A inferência de coisas exteriores às nossas próprias sensações pode ser justificada por regularidades que obtemos dentro das sensações. Quando vemos um gato, por exemplo, certas experiências, como a audição dos sons que ele emite, a visão que temos dele, a sensação de seu pêlo ao toque, são notavelmente correlacionadas. Elas coexistem no mesmo tempo e lugar sempre que percebemos um gato. Do mesmo modo, quando dois observadores se deparam com um gato, há correlações notáveis entre as percepções de ambos. A melhor hipótese para explicar tais regularidades parece ser a de que há uma entidade que as causa, num mundo exterior a nossas mentes. $O$ argumento contra 0 solipsismo pode apoiar-se, nesses termos, num argumento abdutivo, numa inferência da melhor explicação (Sober 1994:28). A questão em pauta nas teses acima não é, necessariamente, a negação da realidade exterior à mente, mas os limites que a natureza da percepção e da linguagem coloca para a proposição de relações entre nossas construções cognitivas e uma realidade extra-lingüística.

Uma interpretação razoável das teses epistemológicas do construtivismo pode ser formulada nos seguintes termos: não há maneira de o homem conhecer o mundo sem transformá-lo, de um lado, porque a percepção sensorial é ativa, e não passiva (Edelman 1987, 1989, 1992; Sacks 1995; El-Hani \& Pereira 2001), de outro, porque o ser humano está sempre inserido na linguagem e, assim, não pode ter acesso a não-sentenças (ou nãocrenças) que tornem suas sentenças (ou crenças) verdadeiras (Davidson 1984, Rorty 1991). Nossa linguagem e nossa mente "penetram tão profundamente no que chamamos de 'realidade' que o próprio projeto de representarmos a nós mesmos como 'mapeadores' de algo 'independente da linguagem' está fatalmente comprometido desde o começo" (Putnam 1990:28. Grifo no original). O mundo, quando conhecido, é reconstruído pelo sujeito e é muito difícil, senão impossível, avaliar a correspondência entre as construções cognitivas e a realidade. Este é um ponto importante, na medida em que afasta o construtivismo de quaisquer ecos solipsistas. Contudo, é também importante não perder de vista que idéias como a de que o sujeito é passivo diante do mundo ou de que a mente é o espelho da natureza, que poderiam ser caracterizadas como anti-construtivistas, são de tal modo ingênuas que, em sentido estrito e literal, não as encontramos em quaisquer filósofos importantes. Não temos como estender este argumento no presente artigo, mas gostaríamos, de qualquer modo, de destacar que, ao criticar-se posições anticonstrutivistas, é conveniente não nos prendermos ao que Peirce (1955) chama de 
'argumento do homem de palha' (strawman argument), ou seja, um argumento tão fraco que refutá-lo se torna uma trivialidade.

O construtivismo tem-se valido, na esfera educacional, de 'slogans' dos quais é difícil discordar, mas que, com o tempo, passaram a ter entendimento cada vez mais literal, até esvaziarem-se de significado. Por exemplo, o slogan de que 'o professor deve trabalhar a partir dos interesses dos alunos' encerra, em si, muita ambigüidade e pode acabar sendo entendido, como de fato já o foi em diversos contextos, como uma certa forma de premonição sobre o papel dos alunos no próprio planejamento das atividades de sala de aula. Uma pergunta óbvia recairia sobre a origem do 'interesse espontâneo' e, como afirma Carvalho (2001: 101), "não seria ocioso ponderar, que, ao contrário da visão sugerida pelo slogan, parte considerável do trabalho docente consiste, de fato, na tentativa de despertar em seus alunos novos interesses e não necessariamente vincular seu trabalho a interesses preexistentes e nem sempre compatíveis com os objetivos das instituições escolares."

O construtivismo educacional, de um ponto de vista mais geral, é um movimento heterogêneo, podendo ser dividido, no mínimo, nas variedades pessoal e social (Matthews 1997:7). Deve-se notar, contudo, que essas variedades, na prática pedagógica concreta, freqüentemente se confundem. Por vezes, elas se apresentam enoveladas em ambigüidades que conduziriam inexoravelmente à conclusão de que a adoção de perspectivas construtivistas na prática pedagógica implicaria renunciar à distinção entre conceitos certos e errados, desde a perspectiva do discurso científico, bem como entre fatos que ocorreram e outros que foram simplesmente inventados. O construtivismo social implica aceitar como intrínseca e igualmente válidas as cosmologias dos zunis ${ }^{1}$ e dos desâna ${ }^{2}$, em relação às de Copérnico e Galileu. No entanto, muitos livros didáticos ensinaram os alunos, durante anos, que o inverno e o verão ocorriam devido à proximidade ou ao afastamento da Terra em relação ao Sol. Mais do que um 'argumento do homem de palha', tal defesa, que se vale de uma tese aparentemente progressista ("todo conhecimento é igualmente válido"), foi classificada como 'argumento sem colesterol' por Bizzo \& Kawasaki (1999:30-31 ${ }^{3}$ ), ou seja, uma asserção que se vale da ambigüidade como forma de convencimento, chamando a atenção para as partes obviamente corretas de um argumento para induzir a aceitação de todo um raciocínio. Não se trata, com isso, de afirmar-se que cosmologias tradicionais nada têm a ensinar-nos. Tem sido repetidamente demonstrada a complexidade do conhecimento tradicional sobre a natureza (ver, por exemplo, Lévi-Strauss [1966]1989, Berlin 1992, Medin \& Atran 1999). Por exemplo, o corpo de conhecimentos de culturas tradicionais, incluindo suas cosmologias, tem sido relacionado a práticas de manejo de recursos naturais que freqüentemente (ainda que nem sempre) se mostram sustentáveis e, de acordo com muitos etnoecólogos, podem contribuir, inclusive, para o desenvolvimento de modelos mais sustentáveis de exploração de recursos pelas sociedades ocidentais modernas (ver, por exemplo, Toledo 1990, 1992; Caballero 1994; Marques 1995; Bandeira 1996, 2002). O que temos em vista é somente a tese de que o conhecimento escolar de Ciências tem como

\footnotetext{
${ }^{1}$ Tribo da América do Norte.

2 Tribo indígena do Alto Rio Negro.

${ }^{3} \mathrm{O}$ artigo introduz o conceito de "persuasão que se vale da reconhecida falta de conhecimento de causa do grupo a ser persuadido" e que pode levar à aceitação de afirmações erradas. O exemplo dado é o do "óleo sem colesterol', inscrição comum em muitos produtos vegetais, que pode conduzir pessoas a consumirem alimentos
} 
parâmetro necessário o conhecimento aceito de maneira majoritária pela comunidade científica de uma dada época, a partir do qual deverá ser feita a transposição de conceitos, teorias, hipóteses etc. para o contexto das escolas (para uma defesa desta tese da perspectiva do conceito de 'transposição didática', ver Lima-Tavares \& El-Hani 2001).

Geelan propôs, em 1997, uma tipologia ou um 'modelo bidimensional' das posições construtivistas, baseado nos seguintes critérios:

(i) a ênfase sobre a natureza pessoal ou social da construção do conhecimento;

(ii) a opção por uma visão mais objetivista ou mais relativista da natureza da ciência.

Ele organizou uma série de artigos construtivistas num sistema de coordenadas cartesianas representando os critérios acima e identificou os seguintes quadrantes:

(1) Social-objetivista: Geelan faz a ressalva de que nenhuma perspectiva construtivista pode ser considerada inteiramente objetivista — isso seria praticamente uma contradição em termos -, afirmando que a qualificação 'objetivista' pretende destacar que os artigos incluídos neste quadrante, escritos, por exemplo, por Solomon e Tobin, não problematizam a natureza da 'verdade' científica e a existência de uma realidade independente do sujeito cognoscente na mesma extensão que aqueles citados no lado 'relativista' do diagrama. O enfoque dos autores citados recai sobre as interações sociais na sala de aula, de modo que eles tendem a não problematizar o conhecimento científico, tratando-o como uma construção consensual na qual os estudantes devem ser socializados;

(2) Social-relativista: os artigos incluídos neste quadrante, escritos por Cobern, Taylor, Gergen, O'Loughlin e Steier, enfatizam a natureza social do conhecimento científico, relativizando-o;

(3) Pessoal-relativista: Geelan observa que não é o caso de que os autores situados neste e no próximo quadrantes não reconheçam a influência social sobre a aprendizagem. Trata-se, antes, de que os artigos incluídos nestas categorias se ocupam sobretudo da cognição individual, e não tanto de processos sociais. O construtivismo radical de von Glasersfeld, por exemplo, é caracterizado por uma visão relativista da ciência e menciona a interação social, mas de uma maneira que concede à cognição individual uma posição central na própria relação com o outro;

(4) Pessoal-objetivista: Esta posição inclui artigos de Driver, Fosnot e Pines \& West. Muitos métodos 'construtivistas' de instrução e a maior parte da literatura sobre mudança conceitual são classificados nesta categoria. Preocupados primordialmente com o Ensino de Ciências e não com epistemologia, eles tendem a considerar o conhecimento científico como um corpo de noções dadas que devem ser aprendidas pelos alunos.

Apesar de ser possível identificar-se várias formas de construtivismo, todas elas compartilham, quanto à compreensão da aprendizagem, os seguintes princípios gerais (Resnick 1983):

ricos em gorduras, acreditando, erroneamente, que não estejam contribuindo para a elevação do nível de seu colesterol sistêmico. 
(i) o aluno, quando aprende de maneira significativa, não reproduz simplesmente o que lhe foi ensinado, mas constrói significados para suas experiências;

(ii) compreender algo supõe estabelecer relações entre o que se está aprendendo e o que já se sabe;

(iii) toda aprendizagem depende de conhecimentos prévios.

É comum que modelos de instrução sejam derivados diretamente das idéias construtivistas sobre a aprendizagem, resultando em propostas pedagógicas que buscam promover a evolução conceitual tipicamente com o seguinte procedimento (ver Millar 1989, Gil-Pérez 1993):

(1) Levantamento das concepções prévias dos alunos;

(2) Esclarecimento e intercâmbio de idéias entre os aprendizes;

(3) Criação de conflitos cognitivos;

(4) Construção de novas idéias; e

(5) Revisão do progresso alcançado e aplicação do que foi aprendido a outros contextos.

No entanto, a teoria construtivista da aprendizagem não está associada necessariamente a um modelo de instrução particular (Millar 1989). Um modelo de instrução informado pelas idéias construtivistas não precisa concretizar em sala de aula as etapas do processo interno pelo qual o sujeito confere significado a suas experiências. A mobilização das concepções prévias, eventuais conflitos cognitivos e a construção de novas idéias são processos que têm lugar na mente do aprendiz, sempre que há aprendizagem significativa, independentemente do modelo de instrução. A teoria construtivista da aprendizagem tem como conseqüência o requisito de que os conteúdos sejam ensinados de tal maneira que, em cada contexto particular, a probabilidade de envolvimento ativo dos aprendizes seja maximizada, dado que, quando isto ocorre, é mais provável que eles tenham sucesso no trabalho intelectual necessário para a construção e reconstrução de significados. Não é razoável pensar-se que um decalque das etapas internas que, de acordo com as proposições acima, estão envolvidas na aprendizagem num modelo 'construtivista' de instrução possa ser, em todas as situações de sala de aula, a abordagem mais adequada e/ou bem sucedida. O procedimento sintetizado nas etapas 1-5 pode, por exemplo, ser muito útil no ensino de um conjunto de conceitos científicos que dependem, para que sejam aprendidos, de uma reestruturação das idéias prévias dos estudantes, mas não parece razoável elegê-lo como a abordagem mais eficaz em todos os casos.

O construtivismo tem sido, nas duas últimas décadas, a influência mais marcante no campo da educação. Autores como Tobin (1993), Resnick (1983), Novak (1988), Gil-Pérez (1993) etc. vêem o construtivismo como um 'paradigma' nas ciências da educação. Mas o construtivismo pode ser considerado um paradigma? ${ }^{4}$ Mortimer (1996) argumenta que o

\footnotetext{
${ }^{4}$ Entendemos 'paradigmas' aqui como realizações científicas universalmente reconhecidas que, durante algum tempo, servem como matrizes disciplinares e fornecem modelos de problemas e soluções para a comunidade de praticantes de uma determinada ciência (Kuhn [1970]1996, p. x). Para uma discussão detalhada do conceito, ver a obra original de Kuhn e os ensaios reunidos em Lakatos \& Musgrave [1970](1979), particularmente Masterman [1970](1979), que discute os vários significados do termo 'paradigma' na obra de Kuhn. Ver tb. HoyningenHuene (1993).
} 
construtivismo começou a dar sinais de esgotamento antes de poder ser visto como um paradigma. Nos últimos anos, uma quantidade crescente de artigos criticando aspectos filosóficos, psicológicos e pedagógicos do construtivismo tem sido publicada. Solomon (1994) chega a falar em "ascensão e queda do construtivismo". Para muitos educadores, o construtivismo se apresenta como um todo relativamente integrado, uma alternativa simples e superior às epistemologias e abordagens de ensino transmissivas. No entanto, quando se examina o construtivismo de maneira mais profunda, percebe-se uma grande variedade de abordagens e visões diferenciadas congregadas sob este rótulo (ver acima).

O consenso construtivista na educação está relacionado, em parte, ao reconhecimento de que diversas propostas apresentadas como modelos distintos expressam, a despeito de suas diferenças, uma concordância em torno das teses identificadas como o núcleo do programa construtivista (Gil-Pérez 1993). Entretanto, as teses nucleares do construtivismo são tão genéricas que se mostram consistentes com uma diversidade de abordagens pedagógicas. Millar (1989) comenta que um dos motivos pelos quais o construtivismo foi tão prontamente aceito na educação científica é o de que seus princípios básicos nada têm de excepcionais. Matthews (1997) considera que as posições do construtivismo educacional são 'lugares-comuns pedagógicos', cujo reconhecimento remonta pelo menos a Sócrates. Isso reforça a idéia de que o construtivismo pode congregar tendências de pensamento comprometidas com posições que, em outros aspectos, são radicalmente diferentes, como, por exemplo, epistemologias idealistas e realistas. Assim, o consenso em torno das suposições centrais do construtivismo pode não ser suficiente para delimitar um domínio paradigmático único, não sendo mais que o resultado de pontos de concordância entre abordagens diferentes (ver, p. ex., Carvalho 2001).

Quando se comenta, portanto, sobre a crise do construtivismo, uma interpretação que não pode ser descartada é a de que tal crise estaria relacionada não à superação de um paradigma, mas a circunstâncias históricas que favoreceram a predominância de diferenças em relação às concordâncias entre as diversas formas de construtivismo, que nunca teriam estado de fato reunidas num paradigma genuíno. Uma eventual queda do construtivismo não significaria, então, uma necessária ruptura com as teses citadas acima, visto que elas poderiam ser mantidas na ausência do rótulo construtivista.

Neste artigo, examinamos duas formas influentes de construtivismo, a mudança conceitual - situada por Geelan no quadrante 'pessoal-objetivista' - e o construtivismo contextual - situado no quadrante 'socialrelativista'. Não obstante a concordância quanto a um núcleo de proposições sobre a aprendizagem, essas posições apresentam diferenças notáveis, o que ilustra como perspectivas que se mostram diversas em muitos aspectos podem ser congregadas sob o rótulo construtivista. A tensão entre essas duas formas de construtivismo é particularmente interessante, em vista da tendência corrente de movimento dos construtivistas do quadrante 'pessoalobjetivista' para posições 'social-relativistas', como o construtivismo contextual (Geelan 1997).

\section{Mudança Conceitual}


O modelo da mudança conceitual surgiu de uma analogia entre o crescimento do conhecimento científico e a aprendizagem das ciências (Posner et al. 1982:211). Este modelo é, pois, uma extensão metafórica (McMullin 1976) da compreensão da mudança conceitual na chamada nova filosofia da ciência para o domínio das teorias do ensino e da aprendizagem. A influência mais notável foi a de Kuhn ([1970]1996), com sua descrição da história das ciências como uma alternância de períodos de ciência normal e revolução científica.

Ao longo da década de 1980 e da primeira metade da década de 1990, 'mudança conceitual' se tornou praticamente sinônimo de 'aprender ciências' (Niedderer et al. 1991), alimentando o que já se chamou de "indústria de misconceptions" (Bizzo 1998:33-34). Como concluiu Wandersee em 1993, numa análise do diretório de membros da National Association for Research in Science Teaching (NARST), grande parte dos pesquisadores considerava, então, a mudança conceitual o foco emergente no ensino de Ciências. Ao longo das duas últimas décadas, numerosas abordagens de ensino apoiadas na mudança conceitual foram propostas e testadas (ver, e.g., Scott et al. 1992). Estas propostas se depararam, contudo, com um número significativo de fracassos, concernentes à dificuldade de suscitar numa parte significativa dos alunos a compreensão dos conceitos científicos, bem como ao retorno de outra parte às suas concepções prévias, alguns meses após os episódios de ensino (ver, p. ex., Gauld 1986; White \& Gunstone 1989; Cobern 1996). Além disso, críticas vigorosas foram feitas às propostas apoiadas no modelo de Posner e colaboradores, como, por exemplo, a de que se apoiavam na perspectiva de uma cognição 'fria', na qual não se tinha na devida conta os fatores motivacionais e contextuais envolvidos no ensino e na aprendizagem (Pintrich et al. 1993), ou a de que não davam a devida atenção à relação entre o conhecimento científico e a visão de mundo dos alunos (ver adiante). Em 1992, dois proponentes originais do modelo, Strike e Posner, apresentaram uma versão revisada, na qual os fatores motivacionais e contextuais, por exemplo, foram considerados em maior detalhe.

O modelo de Posner e colaboradores apresenta dois componentes principais: (i) as condições nas quais a mudança conceitual provavelmente ocorrerá; e (ii) a ecologia conceitual do aprendiz, que propicia o contexto na qual a mudança conceitual pode ter lugar (Hewson \& Thorley 1989:541).

\subsection{As Condições da Mudança Conceitual}

Posner e colaboradores (1982) descrevem quatro condições que parecem ser aspectos comuns na maioria dos casos de acomodação de um novo conceito: inteligibilidade, plausibilidade, fertilidade e insatisfação (Ver tb. Hewson 1981, Hewson \& Thorley 1989). As três primeiras condições compõem o status de uma concepção. Quando uma concepção é inteligível para um indivíduo, ele é capaz de entender o que ela significa, encontrar uma maneira de representá-la, compreender como a experiência pode ser estruturada a partir dela e explorar suas possibilidades. Uma concepção inteligível será também plausível para o indivíduo, caso pareça ter a capacidade de resolver anomalias com as quais se defronta uma concepção anterior, mostrando-se, além disso, consistente com as demais concepções na ecologia conceitual e adquirindo significado a partir delas. $O$ significado de uma concepção emerge, então, de suas conexões com os demais elementos 
da rede de conceitos que constitui a ecologia conceitual do indivíduo. Nesta situação, o indivíduo provavelmente afirmará que a concepção é verdadeira. Uma concepção inteligível será também fértil, se o indivíduo considerar que ela traz algo de valioso para ele, resolvendo problemas que de outro modo lhe pareceriam insolúveis, apresentando poder explicativo e sugerindo novas possibilidades, direções, idéias etc.

A inteligibilidade constitui a pedra basilar do status de uma concepção. É razoável pensar-se, de fato, que uma concepção ininteligível não pode ter qualquer status: como uma concepção que alguém sequer entende poderia mostrar-se plausível ou fértil aos seus olhos? A inteligibilidade é, contudo, uma condição necessária mas não suficiente para a acomodação. As quatro condições somente são suficientes para uma acomodação quando consideradas em conjunto.

A quarta condição da mudança conceitual é a insatisfação. Uma concepção é fonte de insatisfação para um indivíduo quando ela é contra-intuitiva, pouco plausível ou fértil, ou, ainda, quando cria dificuldades ou bloqueia suas possibilidades de compreensão. Uma vez insatisfeito com uma dada concepção, a expectativa é a de que o aprendiz a elimine de sua ecologia conceitual. $\mathrm{O}$ objetivo das estratégias para mudança conceitual é, precisamente, produzir no estudante, mediante a manipulação pelo professor de situações conflitivas, uma insatisfação com suas concepções prévias e, eventualmente, uma substituição destas por idéias científicas.

O aspecto central da mudança conceitual reside na modificação simultânea do status das concepções alternativa e científica. Supondo-se que uma concepção alternativa se encontra em conflito com uma concepção científica, é preciso diminuir o status da primeira, sobretudo sua plausibilidade e fertilidade, e, simultaneamente, aumentar o status da segunda (Hewson \& Thorley 1989:543). Uma das estratégias mais usadas é a proposição de situações conflitivas, com o intuito de produzir no aprendiz uma insatisfação com suas concepções prévias. O sucesso de uma estratégia para mudança conceitual é diretamente dependente da eficácia com que se consegue estas modificações de status. Os aprendizes não abandonam suas concepções alternativas através da simples exposição das concepções científicas com as quais elas se encontram em conflito. Na maioria dos casos, as declarações do professor não são incorporadas na memória de longo termo e/ou são assimiladas como proposições destituídas de significado profundo, uma mera fachada de conhecimento que coexiste por algum tempo - em especial, enquanto persiste a pressão da avaliação - com a crença alternativa mais profundamente arraigada. Entretanto, a mudança conceitual usualmente requer mais do que uma simples adição transitória. Ela envolve o reconhecimento pelo aprendiz das crenças preexistentes em sua ecologia conceitual, uma apreciação de seu valor e de sua precisão em face das novas informações e uma decisão consciente de restruturar o conhecimento. Pode-se apreciar, assim, a dificuldade de alcançar a mudança conceitual, em especial numa estrutura de avaliação como é freqüentemente o caso - na qual o aprendiz pode ser recompensado por fachadas de conhecimento.

\subsection{Ecologia Conceitual}

Posner e colaboradores (1982) tomaram emprestada uma expressão de Stephen Toulmin, 'ecologia conceitual', para referir-se aos conceitos que governam a mudança conceitual. A metáfora da ecologia conceitual se refere ao conjunto de conhecimentos 
prévios que propicia o contexto no qual a acomodação e assimilação de novas idéias deve ter lugar. Pintrich e colaboradores (1993) examinam criticamente as suposições que apoiam a metáfora da ecologia conceitual. Muitos dos aspectos da ecologia conceitual constituem, para o indivíduo, um conhecimento tácito (Polanyi 1964), contendo suposições implícitas que nunca ou raramente são examinadas - interpretações naturais (Feyerabend 1975) —, mas influenciam todos os atos de significação. Os seguintes itens são citados por Posner e colaboradores (1982:214-215) como determinantes particularmente importantes da direção de uma acomodação: anomalias; analogias e metáforas; compromissos epistemológicos (ideais explicativos e visões gerais sobre o caráter do conhecimento); crenças e conceitos metafísicos sobre a ciência e da ciência; e outros conhecimentos. Dois aspectos da ecologia conceitual são particularmente importantes no processo de mudança conceitual: as anomalias e as suposições fundamentais sobre a ciência e o conhecimento. Estas últimas constituem a base sobre a qual são feitos julgamentos sobre as novas concepções (Posner et al. 1982:223). Isso sugere um papel importante para a visão de mundo dos aprendizes (ver abaixo).

\subsection{Modos de Evolução Conceitual}

Dois modos de evolução conceitual são distinguidos por Posner e colaboradores (1982:212): a assimilação, por eles comparada à ciência normal kuhniana, na qual os estudantes fazem uso de conceitos preexistentes para lidar com novos fenômenos; e a acomodação, que seria análoga às revoluções científicas. Hewson (1981), por sua vez, se refere à troca conceitual, correspondente à acomodação, na qual haveria uma reestruturação profunda da ecologia conceitual, ocorrendo ruptura do indivíduo com suas concepções prévias, e à captura conceitual (assimilação), na qual a ecologia conceitual seria preservada em seus aspectos mais fundamentais, sendo apenas enriquecida com novas concepções.

Uma questão relevante diz respeito a como esses dois modos de evolução conceitual se relacionam à compreensão piagetiana dos processos de assimilação e acomodação. Piaget entende a adaptação do organismo ao meio como "... um equilíbrio entre a assimilação e a acomodação" (Piaget ([1966]1987:17. Ênfase no original) e concebe a adaptação intelectual no sentido de ".. um estabelecimento de equilíbrio progressivo entre um mecanismo assimilador e uma acomodação complementar" (Piaget [1966]1987:18). A assimilação consiste, para ele, numa relação em que o organismo, ao incorporar elementos do meio, conserva o ciclo de sua organização, coordenando aqueles elementos de modo a incorporá-los nesse ciclo sem destrui-lo. A inteligência é, então, assimilação na medida em que incorpora em seus quadros os dados da experiência, assimilando a realidade exterior às formas devidas à atividade do sujeito, tornando a realidade compreendida porque integrada aos esquemas já estabelecidos pelo organismo. Trata-se, em suma, de um conjunto de processos nos quais os objetos são assimilados ao sujeito (Piaget [1966]1987:17-18). A vida mental não se limita, contudo, à assimilação, incluindo também processos de acomodação, nos quais mudanças do meio resultam em experiências às quais o organismo só logra adaptar-se se modificar o ciclo de sua organização. Como argumenta Piaget, a assimilação nunca pode ser pura, porque, ao incorporar novos

elementos nos esquemas anteriormente disponíveis, a inteligência modifica 
incessantemente tais esquemas para ajustá-los às novas experiências. No entanto, esse trabalho de acomodação só é possível em função de processos de assimilação, de modo que as coisas nunca são conhecidas em si mesmas, mas sempre segundo o crivo dos esquemas de assimilação do sujeito (Piaget [1966]1987:17-18). Pode-se concluir, em suma, que as noções de assimilação (ou captura conceitual) e acomodação (ou troca conceitual), na mudança conceitual, preservam basicamente o significado dado a estes termos por Piaget.

A expectativa de um rompimento dos indivíduos com suas concepções prévias é tão central para a noção de mudança conceitual que Posner e colaboradores a definiram de uma maneira que põe em destaque a idéia de troca conceitual, referindo-se a ela como

"... o processo pelo qual os conceitos centrais e organizadores de uma pessoa se modificam de um conjunto de conceitos a outro, incompatível com o primeiro" (Posner et al. 1982:211).

Hewson e Thorley (1989) afirmam que concepções conflitantes não podem ser simultaneamente plausíveis para uma mesma pessoa. As contradições seriam resolvidas mediante a integração das velhas concepções às novas ou, não sendo isto possível, pela substituição das primeiras. Parece-nos difícil, contudo, sustentar que o conjunto total de estados intencionais atribuídos a uma pessoa não possa abrigar contradições, a não ser que ela se encontre em meio a um processo de evolução conceitual. Em nossa visão, é possível que crenças contraditórias convivam na ecologia conceitual de um indivíduo, desde que sejam empregadas em contextos diferentes. Dan Sperber, por exemplo, ao estudar os Dorzé, observou que aos olhos desses pastores etíopes

"o leopardo é um animal cristão, que respeita os jejuns da lgreja copta, observância que na Etiópia é o teste principal da religião; mas nem por isso um Dorzé está menos preocupado em proteger seu gado na quarta e na sexta-feira, dias de jejum, do que nos outros dias da semana; ele acredita que os leopardos jejuam e comem todos os dias; os leopardos são perigosos todos os dias: ele sabe disso por experiência; são cristãos: a tradição lho garante" (citado por Veyne 1984:9).

Os Dorzé acreditam que o leopardo come e não come nos dias de jejum observados pela Igreja copta. Os Gregos acreditavam e ao mesmo tempo não acreditavam em seus mitos (Veyne 1984). Não seria o caso de concluir-se, em vista dessas crenças conflitantes, que os Dorzé sejam irracionais. Tampouco que os antigos Gregos o eram. Cada uma das idéias é empregada no contexto conveniente. A presença de tais crenças conflitantes no pensamento dos Gregos e dos Dorzé deve ser interpretada como evidência de um conhecimento em processo de reequilibração? Esta é uma interpretação possível. Não obstante, há outra interpretação plausível, na qual as contradições são consideradas um aspecto comum do pensamento humano, mesmo quando em equilíbrio. Neste ponto, concordamos com Matthews:

"Não há qualquer dúvida de que, subjetivamente, dentro de um indivíduo, todos os tipos de visões de mundo mutuamente inconsistentes podem coexistir. Os indivíduos freqüentemente não têm consciência das contradições. Mesmo quando as contradições entre compromissos intelectuais são aparentes, os indivíduos podem viver com enormes quantidades de dissonância cognitiva" (Matthews 1994b:185). 
Formas de construtivismo: mudança conceitual e construtivismo contextual

Pode até ser que os pastores, se pressionados, optem por uma das crenças conflitantes, mas isso só mostra que, diante de uma perturbação externa, a estabilidade de seu pensamento será rompida. É provável, inclusive, que eles se sintam desconfortáveis em vista de uma escolha que poderia parecer-lhes totalmente dispensável. Este exemplo traz lições importantes para o Ensino de Ciências. Quando a sala de aula se torna palco de conflitos entre as visões de mundo dos estudantes e as concepções científicas, a alternativa mais racional não parece ser a de forçá-los a uma opção, mediante conflitos cognitivos, mas a de reconhecer e explicitar domínios particulares do discurso nos quais as concepções científicas e as idéias dos alunos têm, cada qual no seu contexto, alcance e validade.

\subsection{Conflitos Cognitivos}

As situações conflitivas têm um papel fundamental na mudança conceitual. Elas resultam da incapacidade do sujeito de resolver problemas produzidos em sua interação com o meio, sendo utilizadas como ferramentas para a diminuição do status das concepções prévias. Essas situações são planejadas de modo a explicitar ou produzir anomalias entre as concepções alternativas e as experiências do aprendiz, devendo suscitar uma insatisfação com o conhecimento prévio e possibilitar, assim, que as concepções científicas sejam introduzidas numa posição vantajosa para a resolução do problema em pauta. As estratégias para mudança conceitual estão baseadas, portanto, numa espécie de manipulação das situações de aprendizagem pelo professor, de modo a suscitar nos alunos, a partir de tentativas mal sucedidas de assimilação de uma experiência ou nova concepção em sua ecologia conceitual, a decisão de acomodar o conhecimento científico, mesmo que às expensas de suas idéias anteriores.

Uma situação conflitiva comporta, no entanto, alternativas à acomodação (Posner et al. 1982:221):

(1) Rejeição da teoria observacional; ${ }^{5}$

(2) Suposição de que os achados experimentais não são relevantes como desafios às concepções prévias;

(3) Compartimentalização do conhecimento, de modo a evitar que a nova informação entre em conflito com as concepções prévias. Cobern (1996) chama esta situação de apartheid cognitivo (ver adiante);

(4) Assimilação da nova informação à ecologia conceitual preexistente, de tal modo que a acomodação é evitada por uma reinterpretação que torna aquela informação consistente com as idéias anteriores do aprendiz. Nesse caso, o estudante utiliza conceitos preexistentes em sua ecologia conceitual para interpretar a situação conflitiva de tal modo que o conflito seja evitado por meio de uma série de hipóteses auxiliares que tornam as observações feitas compatíveis com suas concepções prévias. Desse modo, a acomodação, a reestruturação profunda da ecologia conceitual, pode ser evitada, não ocorrendo rompimento com as concepções prévias. Considere-se, por exemplo, a possibilidade de que um aluno, quando confrontado com situações de conflito cognitivo entre sua visão criacionista e a teoria neodarwinista da evolução, elabore o argumento de que aceita esta última teoria, desde que acompanhada da suposição de que as

\footnotetext{
${ }^{5}$ Sobre o papel das teorias observacionais, ver Lakatos ([1970]1979).
} 
Formas de construtivismo: mudança conceitual e construtivismo contextual

mutações não acontecem de maneira não-dirigida ou cega, mas são produzidas pelo Criador, de modo que, no fim das contas, o processo evolutivo seria dirigido por este último. Não se pode dizer, nesse caso, que tenha ocorrido acomodação, no sentido dado ao termo por Posner e colaboradores, da teoria neodarwinista.

\section{Construtivismo Contextual}

Na tipologia de Geelan, o construtivismo contextual está situado na posição oposta ao quadrante pessoal-objetivista, no qual se encontra a mudança conceitual. De fato, as diferenças entre essas duas formas de construtivismo são notáveis, podendo ser entendidas como aspectos da divergência entre uma tendência que concede um papel central ao indivíduo na aprendizagem, entendendo o conhecimento científico como algo dado, a ser por ele aprendido, e outra, que salienta o papel da cultura no desenvolvimento e na validação das crenças individuais e procura inserir a ciência no contexto sócio-cultural, considerando-a uma segunda cultura para os aprendizes.

\subsection{O conceito de visão de mundo}

O conceito de 'visão de mundo', tomado da antropologia cultural, tem um papel central no construtivismo contextual. A visão de mundo de um indivíduo corresponde à organização fundamental de sua mente, incluindo um conjunto de pressupostos subjacentes a seus atos, seus pensamentos, suas disposições, seus juízos etc. Esses pressupostos têm um caráter tanto ontológico como epistemológico, constituindo critérios para a apreciação de quais idéias ou crenças são consideradas válidas e relevantes, ou, nos termos de Cobern, têm força e alcance para o indivíduo. Diz-se que um conceito ou uma crença tem força se ele ocupa uma posição central, e não marginal, no pensamento do indivíduo, e alcance, caso se mostre relevante para ele numa grande variedade de contextos (Cobern 1996:580). O construtivismo contextual comporta respostas para as seguintes questões de Posner e colaboradores (1982:213): "que tipos de conceitos tendem a governar o processo de acomodação?"; "quais são os aspectos de uma ecologia conceitual que governam a seleção de novos conceitos?"

Cobern (1991) adaptou o estruturalismo lógico para a pesquisa em educação, utilizando o modelo de visão de mundo de Kearney (1984). Trata-se de um modelo sistêmico, que tem na devida conta as interações complexas, não-aditivas, dos diferentes componentes de uma visão de mundo. Para Cobern, o poder do modelo lógico-estruturalista se encontra em sua estrutura integrada, composta pelas seguintes categorias universais: Eu, Outro, Relação, Classificação, Causalidade, Espaço e Tempo (Kearney 1984:72-106). O esqueleto de uma visão de mundo é, de acordo com o modelo, a oposição e integração do Eu e do Outro (Kearney 1984:106). As demais categorias universais são derivadas deste esqueleto. A categoria Relação corresponde à maneira como é entendida a relação entre o Eu e o Outro, bem como as relações entre elementos dentro do Eu e do Outro. A dimensão da Classificação se relaciona às principais discriminações dentro do Outro. Note-se que, enquanto a Classificação é relativamente estática, a Relação é um aspecto mais dinâmico da visão de mundo. Deste aspecto dinâmico da Relação, decorre a categoria universal da 
Causalidade. A Causalidade, por sua vez, depende não apenas da Relação, mas também do Espaço e do Tempo. Um dos elementos mais importantes na categoria Outro é a natureza. Um dos principais objetos dos estudos empíricos realizados por Cobern e sua equipe tem sido as concepções de natureza de professores e alunos (ver Cobern et al. 1999; Cobern 2000). A Figura 1 apresenta um diagrama esquemático das interconexões lógico-estruturais das categorias universais identificadas por Kearney.

Este modelo de visão de mundo deve dar conta, de acordo com Kearney, do principal aspecto relacionado à natureza e ao papel do macro-pensamento organizado culturalmente, a saber, "aquelas suposições cognitivas básicas de uma pessoa, interrelacionadas de forma dinâmica, que determinam grande parte de seu comportamento e de sua tomada de decisões, bem como organizam grande parte de seu corpo de criações simbólicas mito, religião, cosmologia - e a etnofilosofia em geral" (Kearney 1984:1).

Nesses termos, ele define 'visão de mundo' da seguinte forma:

"A visão de mundo de um povo é seu modo de olhar para a realidade. Ela consiste de suposições e imagens básicas que propiciam um modo de pensar o mundo mais ou menos coerente, embora não necessariamente acurado" (Kearney 1984:41).

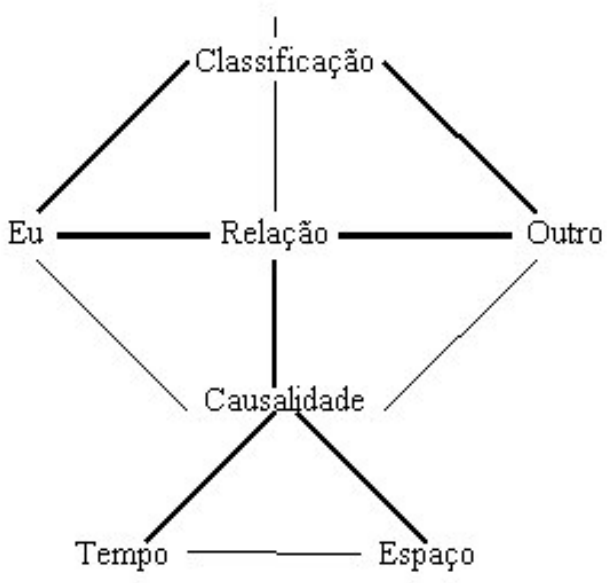

Figura 1: Categorias Universais do Modelo Lógico-Estruturalista de Kearney (1984).

\subsection{Alfabetização científica ou aprendizagem de uma segunda linguagem?}

Tendo-se em vista que a visão de mundo norteia todos os atos de conhecimento, torna-se clara sua importância para o Ensino de Ciências. Uma das teses fundamentais do construtivismo contextual é a de que os aprendizes, seja qual for sua origem, sempre trazem para a sala de aula uma visão de mundo, produzida mediante o contato com sua 
Formas de construtivismo: mudança conceitual e construtivismo contextual

cultura primeira. O que está sendo ensinado deve ser em geral entendido como parte de uma segunda cultura para os aprendizes. Deste ponto de vista, toda educação tem uma natureza multicultural. Se a ciência for entendida como uma segunda cultura para a maioria dos estudantes, como propõem Cobern (1994a, 1996), Aikenhead (1996) e Cobern \& Aikenhead (1998), é provável que a sala de aula seja palco de conflitos entre visões de mundo diferentes. A sala de aula não é um local no qual todos, alunos e professores, estão operando na mesma visão de mundo. Ela é muito mais rica do que usualmente se suspeita, congregando, num único espaço, uma diversidade de formas de pensamento, que podem entrar em choque com maior freqüência do que em geral se admite. A possibilidade de tais conflitos não escapou a Posner e colaboradores, quando eles propuseram o modelo da mudança conceitual:

“... mudanças conceituais fundamentais, chamadas de acomodações, podem envolver mudanças nas suposições fundamentais de uma pessoa acerca do mundo, do conhecimento e do saber, e [...] tais mudanças podem ser difíceis e potencialmente ameaçadoras, particularmente quando o indivíduo está firmemente comprometido com as suposições prévias" (Posner et al. 1982:223).

A educação científica só será bem sucedida, do ponto de vista do construtivismo contextual, se o conhecimento científico encontrar um 'nicho' no meio cognitivo e cultural dos estudantes, ou, nos termos de Posner e colaboradores, em sua ecologia conceitual. A aprendizagem de ciências pode ser comparada, de acordo com Cobern (1996), à aprendizagem de uma segunda linguagem, o que sugere a necessidade de cautela na interpretação de uma metáfora muito utilizada na literatura sobre Ensino de Ciências nos últimos anos, a metáfora da 'alfabetização científica' (scientific literacy). Quando falamos da 'alfabetização' de uma pessoa, pretendemos indicar o processo pelo qual ela se torna capaz de ler e escrever na linguagem própria de sua cultura. No entanto, tendo-se na devida conta a hipótese Sapir-Whorf (ver Cobern 1996), de acordo com a qual pensamento e linguagem são intimamente relacionados, de tal modo que fazer uso de uma certa linguagem implica empregar uma certa maneira de pensar, pode-se concluir que a alfabetização não se limita a estes aspectos. Aprender uma linguagem também significa vir a compreender uma visão de mundo, ainda que não necessariamente adotá-la. O mesmo ocorreria no caso de uma 'alfabetização científica': a pessoa, ao 'alfabetizarse cientificamente', passaria a ver o mundo de uma outra maneira, mesmo que não adotasse uma visão de mundo que pudesse ser caracterizada como 'científica'. Deve-se ter cuidado, contudo, para que as semelhanças subjacentes à metáfora da alfabetização científica não obscureçam diferenças importantes entre o processo de alfabetização propriamente dito e o Ensino de Ciências. Quando uma pessoa se alfabetiza numa linguagem, ela aprende a ler e escrever numa linguagem que ela já fala. No caso da educação científica, a situação é diferente, visto que os aprendizes não falam, na grande maioria dos casos, qualquer linguagem científica. De uma só tacada, eles devem aprender a pensar, falar, ler e escrever numa outra linguagem, que traz consigo uma maneira particular de ver o mundo. Consideremos, além disso, que a ciência se caracteriza por um 'senso incomum' (Cromer 1993) e por sua 'natureza não-natural' (Wolpert 1992), e que o território das ciências naturais é, para os alunos, uma terra inteiramente incógnita, estranha, cheia de termos e conceitos que eles não alcançam, marcada por uma maneira de pensar que não lhes é familiar, na qual pouco ou até mesmo nada do que já conhecem 
Formas de construtivismo: mudança conceitual e construtivismo contextual

pode ajudá-los a aclimatarem-se (cf. Solomon 1994:16). Teremos, assim, a exata dimensão do desafio de ensinar Ciências.

O construtivismo contextual põe em destaque uma dimensão deste desafio que tem sido freqüentemente deixada de lado, a de que os alunos deverão aprender Ciências numa situação na qual já possuem outra linguagem e outra cultura, a nortear suas decisões, suas ações, seus juízos etc.

\subsection{A aprendizagem de Ciências requer a ruptura dos estudantes com suas concepções prévias?}

Uma perspectiva cientificista, na qual a ciência é colocada acima da cultura, pode ser freqüentemente percebida quando se discute a educação científica (ver Bauer 1992, Cobern 1996). Considere-se, por exemplo, a noção de 'troca conceitual', na mudança conceitual. Esta noção se apoia no pressuposto tácito de que alunos, professores e materiais instrucionais compartilham a mesma visão de mundo, propondo que a 'superioridade' das noções científicas poderia ser demonstrada por uma abordagem 'experimental', isolando-se o estudante de outros domínios do conhecimento e controlando-se as condições contextuais, de modo que ele volte toda a sua atenção para a manipulação realizada pelo professor (Pintrich et al. 1993; Cobern 1996). Neste tipo de abordagem, a aprendizagem de Ciências requer a ruptura dos estudantes com sua compreensão do mundo natural. No entanto, se a expectativa no Ensino de Ciências é a de que as pessoas utilizem as idéias científicas em seu cotidiano - como afirmam, inclusive, os projetos de reforma do Ensino de Ciências baseados na 'alfabetização científica' -, estas idéias devem fazer sentido à luz da visão de mundo das pessoas, e não apesar dela (Cobern 1996).

Deve-se considerar, além disso, que pode ser muito difícil demonstrar que explicações científicas sejam 'superiores' às idéias alternativas dos aprendizes, quando estas últimas possuem, para eles, grande força e alcance. A Figura 2 ilustra o efeito orientador da visão de mundo sobre a acomodação das noções aprendidas por uma pessoa. As setas longas representam a orientação da visão de mundo e as pontas de setas, conceitos individuais. Na Figura 2A, três conceitos científicos estão em desacordo com a orientação geral da visão de mundo. Na mudança conceitual, o que se supõe é que, se uma massa 'crítica' de conceitos científicos fosse posta em jogo - mediante situações conflitivas -, o peso conceitual da ciência seria capaz de deslocar a orientação da visão de mundo do aprendiz. Ou seja, as setas longas seriam reorientadas na direção das três pontas de setas que representam os conceitos científicos. As outras pontas de seta iriam, do mesmo modo, reorientar-se ou seriam eliminadas. Uma revolução, no sentido kuhniano, teria lugar e a educação científica teria cumprido seu objetivo de fomentar uma visão de mundo compatível com a ciência ou até mesmo uma 'visão de mundo científica', caso se admita a existência de pessoas que alcancem uma consistência de tal modo plena em seus sistemas de crenças que se possa dizer que elas abraçaram uma visão inteiramente científica, sem qualquer dissonância cognitiva (cf. Cobern 1996). 


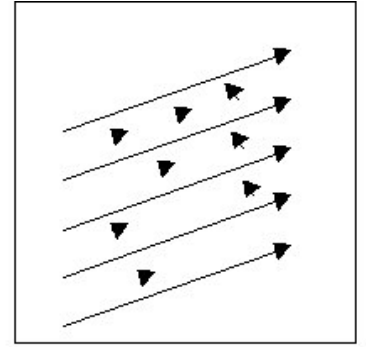

A

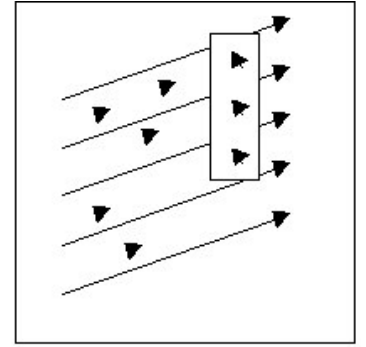

Figura 2: Efeito orientador da visão de mundo (de Cobern, 1996).

É razoável supor-se que há uma massa conceitual crítica que, uma vez alcançada, tenderia a alterar a visão de mundo de um estudante na direção de uma compatibilidade com o discurso científico. O problema é alcançar esta massa conceitual (Cobern 1996:587588). Ela parece ser rara e desigualmente atingida. Usualmente, não ocorre um deslocamento da visão de mundo do estudante graças à aprendizagem de Ciências, mas, ao contrário, os conceitos científicos incompatíveis com sua visão de mundo são postos numa categoria à parte e eventualmente descartados. Cobern (1996) se refere a este fenômeno como apartheid cognitivo. Ele é mostrado na Figura 2B: o aprendiz cria um compartimento para os conceitos científicos incompatíveis com a orientação geral de sua visão de mundo, deixando-os à mão para que possam ser acessados em ocasiões especiais, tal como nos dias de avaliação, mas eles não têm efeito algum sobre sua vida cotidiana e seu modo de pensar. Enquanto ele está sob pressão, estes conceitos sustentam um significado próximo àquele que têm no discurso científico, ou seja, as paredes do compartimento cognitivo são mantidas no lugar. No entanto, assim que a pressão é aliviada, as paredes se rompem e os conceitos científicos ou são eliminados, ou são ressignificados de uma maneira que os torna consistentes com a visão de mundo, ainda que às expensas de seu significado original no discurso científico.

A primeira barreira com que se defronta uma concepção para que venha a ser aceita por uma pessoa é a de que ela deve fazer sentido para aquela pessoa. Este aspecto traz consigo o seguinte problema, que explica, pelo menos em parte, a dificuldade de alterar-se a visão de mundo de um estudante através do Ensino de Ciências: De um lado, a alteração dos conceitos que têm um papel central na ecologia conceitual do estudante requer que uma massa conceitual crítica seja alcançada. De outro, esta massa só pode ser alcançada se o aprendiz conseguir compreender as noções que devem compô-la. No entanto, na medida em que ele se encontra comprometido com conceitos centrais em sua visão de mundo, idéias conflitantes tendem a ser de difícil compreensão. Este paradoxo está associado ao duplo papel das concepções prévias na ecologia conceitual: de um lado, elas freqüentemente conduzem a uma resistência à aprendizagem de noções científicas; de outro, são elas que propiciam o contexto no qual o aprendiz deve julgar a validade e adequação de informações novas e potencialmente conflitantes (Pintrich et al. 1993:170). A massa conceitual necessária para a acomodação pode mostrar-se, diante deste problema, praticamente inatingível. Pode ser apropriado, então, concentrar-se sobre a tentativa de que os alunos compreendam as novas concepções, mesmo que possam eventualmente não acreditar nelas. Embora a visão de mundo de um aprendiz possa acarretar dificuldades para a compreensão de idéias científicas, é razoável pensar-se que ela não representa 
necessariamente um obstáculo para tal compreensão. Em contrapartida, o domínio de um conceito científico também não implica necessariamente a rejeição de uma visão de mundo. Há uma diferença fundamental entre compreensão (ter o domínio de uma noção) e crença (aceitar uma noção como válida ou verdadeira) e a compreensão parece não necessitar da crença (Cobern 1994b, 1996). Um conceito que é completamente compreendido por uma pessoa pode ser por ela rejeitado, por não ter força e alcance no contexto de sua visão de mundo. Em situações de conflito entre a visão de mundo de um estudante e o discurso científico - por exemplo, nos casos de conflito entre educação científica e educação religiosa (ver Mahner \& Bunge 1996; Lacey 1996; Settle 1996; Woolnough 1996; El-Hani \& Sepúlveda 2001; Sepúlveda \& El-Hani 2001; Sepúlveda 2002) —, pode ser vantajoso para o Ensino de Ciências deslocar seus objetivos da promoção de crenças para o estímulo à compreensão do conhecimento científico. Pode-se levar o aluno a compreender os conceitos e as teorias científicas, sem esperar que ele venha a crer naqueles conceitos ou considerar aquelas teorias válidas ou verdadeiras. Não se pode dizer que houve, neste caso, troca conceitual (ver Figura 3). Entretanto, pode-se dizer que o perfil conceitual do aprendiz foi alterado.

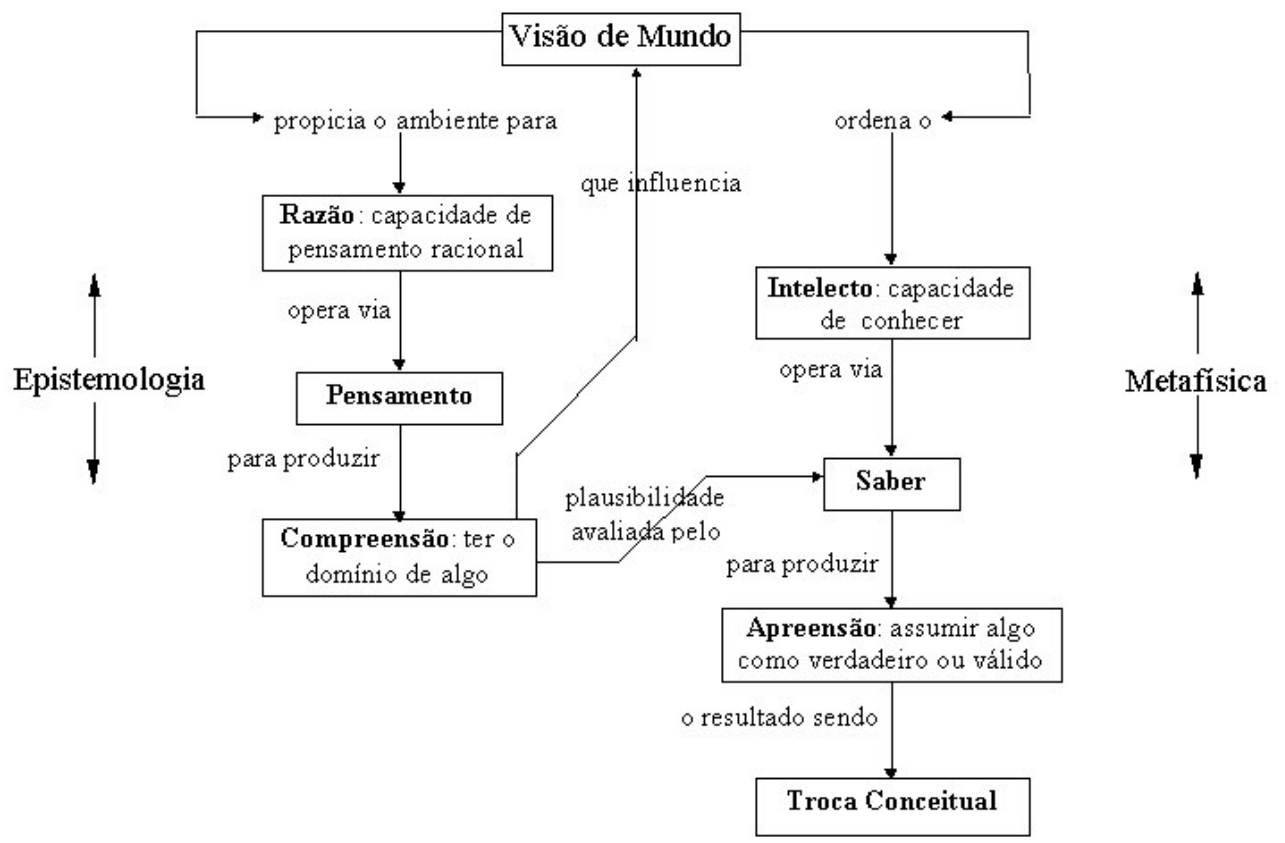

Figura 3. Visão de mundo, compreensão, apreensão e troca conceitual. (Adaptado de Cobern 1996).

\section{Perfis conceituais}

Não é apenas no construtivismo contextual que se defende a transição de um suposto compromisso do Ensino de Ciências com a necessidade de os alunos romperem 
com suas concepções prévias para uma visão alternativa de acordo com a qual a tarefa do professor de Ciências consiste em suscitar nos alunos a compreensão do conhecimento científico e o reconhecimento dos domínios particulares do discurso nos quais as concepções científicas, as noções associadas a outras formas de conhecimento e as idéias de senso comum têm, cada qual, alcance e validade. Esta idéia também é encontrada, por exemplo, no modelo de mudança de perfis conceituais, proposto por Mortimer (1994, 1995, 1996).

O modelo de Mortimer se diferencia do modelo de Posner e colaboradores, entre outros aspectos, por não demandar um rompimento dos alunos com suas concepções prévias. No modelo de mudança de perfis conceituais, a evolução conceitual não é entendida como uma substituição das concepções prévias do aprendiz por idéias científicas, mas como um enriquecimento do espectro de idéias de que ele dispõe para a compreensão de um dado assunto. Na evolução de um perfil conceitual, o domínio de aplicabilidade de cada concepção pode ser delimitado. Nesses termos, pode-se dizer que o Ensino de Ciências deve, sobretudo, mostrar aos alunos como um conjunto de problemas é resolvido da perspectiva científica, ampliando o espectro de possibilidades disponíveis para eles. Agora, a questão de se o aluno acreditará ou não nas concepções científicas, em vez de somente compreendê-las, pode ser apropriadamente entendida como um problema de foro íntimo do aluno, a ser examinado por ele no contexto de sua visão de mundo, à luz das idéias que têm força e alcance para ele. O objetivo do professor de Ciências pode, nesses termos, ser repensado como sendo o de propiciar ao aprendiz condições de desenvolver uma visão de mundo compatível com a ciência, mas não necessariamente uma visão de mundo científica (ver Cobern 1996). Nesse caso, um resultado possível é o de que a ciência venha a tornar-se parte de seu pensamento cotidiano, sem que outros modos de pensar sejam necessariamente eliminados. O modelo de mudança de perfis conceituais admite a possibilidade de que diferentes formas de pensar, mesmo sendo contraditórias, convivam de modo estável na ecologia conceitual de uma única pessoa. Estes aspectos do modelo de Mortimer sugerem a possibilidade de relacioná-lo com proveito com o construtivismo contextual de Cobern.

O modelo de mudança de perfis conceituais parece ser uma ferramenta adequada para reconciliar dois aspectos, em princípio conflitantes, da visão construtivista: a necessidade de ensinar ao aluno um corpo consensual de conhecimentos, próprio de cada ciência, e a natureza pessoal do conhecimento de cada indivíduo (Millar 1989). A idéia de um perfil de concepções permite que se tenha como objetivo, no Ensino de Ciências, tanto que o aluno compreenda um determinado corpo de conhecimentos, como que o conhecimento de cada aluno seja, num sentido bastante forte, o seu conhecimento. Cada aluno continuará, ao longo de todos os episódios de ensino, na posse de seu próprio perfil de concepções, mas este perfil não será mais o mesmo após ele ter aprendido um dado corpo de conhecimentos científicos.

\section{Conclusões}


Neste artigo, a diversidade de formas de construtivismo foi discutida, tomando-se como ponto de partida o modelo bidimensional de formas de construtivismo proposto por Geelan (1997). Após uma análise inicial deste modelo, foram enfocadas de modo particular as tensões entre duas variantes colocadas em posições opostas naquela tipologia, a mudança conceitual e o construtivismo contextual. O modelo da mudança conceitual de Posner e colaboradores foi analisado, destacando-se seu compromisso com a idéia de que os estudantes devem ser levados, ao longo da aprendizagem de Ciências, a um rompimento com suas concepções prévias, usualmente em conflito com as concepções científicas. Esta idéia foi criticada de modo incisivo desde a perspectiva do construtivismo contextual, como pode ser verificado nos trabalhos de seu proponente, Cobern. A mesma crítica foi feita do ponto de vista do modelo de mudança de perfis conceituais, proposto por Mortimer. De nossa parte, situamo-nos neste debate em posição bastante próxima à de Cobern e à de Mortimer, destacando a importância de distinguir claramente entre a compreensão de um conceito ou uma teoria científica por um estudante, relacionada ao domínio de tal conceito ou teoria adquirido ao longo do processo de ensino e aprendizagem, e a aceitação do conceito ou da teoria como válida ou verdadeira. Um estudante pode compreender de maneira precisa, por exemplo, a teoria neodarwinista da evolução, mesmo que não acredite nela. Diante de possíveis conflitos entre as visões de mundo dos estudantes e as concepções científicas na sala de aula, usualmente mais multiculturais do que reconhecemos, não nos parece que a estratégia de forçar os estudantes a assumirem uma posição quanto às suas crenças, indo além dos compromissos com a compreensão, seja a mais apropriada. O reconhecimento e a explicitação de domínios particulares do discurso nos quais as concepções científicas e as idéias dos alunos têm, cada qual no seu contexto, alcance e validade dão vez a uma estratégia que nos parece mais adequada. Deve-se ter, contudo, o devido cuidado de realmente promover uma compreensão das idéias científicas, evitando-se o simples reforço de idéias espontâneas dos estudantes, um resultado que estratégias de instrução construtivistas podem inadvertidamente suscitar.

\section{Agradecimentos}

Os autores agradecem à CAPES, à Universidade Federal da Bahia, ao CNPq/MCT pelo apoio, a Waldomiro José da Silva Filho (FFCH-UFBa) e João Carlos Salles (FFCHUFBa) pelas discussões travadas ao longo da elaboração do artigo, e a dois árbitros anônimos, cujas sugestões contribuíram de maneira significativa para a preparação da versão final do manuscrito. 


\section{Referências Bibliográficas}

AIKENHEAD, G. S. (1996) Science education: border crossing into the subculture of science. Studies in Science Education, 27, 1-52.

BANDEIRA, F. P. S. F. (1996). Um estudo em perspectiva: etnopedologia e etnoecogeografia do grupo indígena Pankararé. Cadernos de Geociências, 5, 107-128.

BANDEIRA, F. P. S. F. (2002). Analisis de Factores que Afectan el Establecimiento y la Estructura Floristica de los Cafetales Rusticos en Dos Areas del Sureste de Mexico. Mexico: UNAM. Tese de Doutorado.

BAUER, H. H. (1992) Scientific Literacy and the Myth of the Scientific Method. Urbana: University of Illinois Press.

BERLIN, B. (1992). Ethnobiological Classification: Principles of Categorization of Plants and Animals in Traditional Societies. Princeton: Princeton University Press.

BIZZO, N. (1998) Ciências: Fácil ou Difícil? São Paulo: Ática.

BIZZO, N.; KAWASAKI. C. S. (1999) Este Artigo Não Contém Colesterol: pelo fim das imposturas intelectuais no ensino de ciências. Projeto, Revista de Educação 1(I):25-34.

CABALLERO, J. (1994). Use and Management of Sabal Palms Among the Maya of Yucatan. Berkeley: University of California. Tese de Doutorado.

CARVALHO, J. S. F. (2001). Construtivismo, Uma Pedagogia Esquecida da Escola. Porto Alegre, Artmed Editora.

COBERN, W. W. (1991) World View Theory and Science Education Research. ManhattanKansas: NARST.

COBERN, W. W. (1994a) World view, culture, and science education. Science Education International, 5(4), 5-8.

COBERN, W. W. (1994b). Point: Belief, understanding, and the teaching of evolution. Journal of Research in Science Teaching (31): 583-590.

COBERN, W. W. (1996) Worldview theory and conceptual change in science education. Science Education, 80(5), 579-610. 
COBERN, W. W. (2000). Everyday Thoughts about Nature. Dordrecht: Kluwer.

COBERN, W. W., AIKENHEAD, G. S. (1998) Cultural aspects of learning science. In: TOBIN, K., FRASER, B. (Eds.). International Handbook of Science Education. Dordrecht: Kluwer.

COBERN, W. W., GIBSON, A. T., UNDERWOOD, S. A. (1999) Everyday thoughts about nature: An interpretive study of 16 ninth graders' conceptualizations of nature. Journal of Research in Science Teaching, 36 (5), 541-564.

CROMER, A. (1993) Uncommon Sense: The Heretical Nature of Science. New York: Oxford University Press.

DAVIDSON, D. (1984) Inquiries into Truth \& Interpretation. Oxford: Clarendon Press.

EDELMAN, G. M. (1987) Neural Darwinism: The Theory of Neuronal Group Selection. New York: Basic Books.

EDELMAN, G. M. (1989) The Remembered Present: A Biological Theory of Consciousness. New York: Basic Books.

EDELMAN, G. M. (1992) Bright Air, Brilliant Fire: On the Matter of the Mind. New York: Basic Books.

EL-HANI, C. N.; PEREIRA, A. M. (2001) Notas sobre percepção e interpretação em ciência. Revista USP, 49, 148-159.

EL-HANI, C. N.; SEPÚLVEDA, C. (2001) Analisando as relações entre educação científica e educação religiosa. I. Professores de ciências podem evitar o fisicalismo? Atas do III Encontro Nacional de Pesquisa em Educação em Ciências (ENPEC).

FEYERABEND, P. K. (1975) Contra o Método. Rio de Janeiro: Francisco Alves.

GAULD, C. (1986) Models, meters and memory. Research in Science Education 16, 49-54.

GEELAN, D. R. (1997) Epistemological anarchy and the many forms of constructivism. Science \& Education, 6(1-2), 15-28.

GIL-PÉREZ, D. (1993) Contribución de la historia y de la filosofia de las ciencias al desarrollo de un modelo de enseñanza/aprendizaje como investigación. Enseñanza de las Ciencias, 11(2), 197-212.

HARRÉ, R. (1992) The Philosophies of Science: An Introductory Survey. Oxford: Oxford University Press.

HEWSON, P. W. (1981) A conceptual change approach to learning science. European Journal of Science Education, 3(4), 383-396.

HEWSON, P. W.; THORLEY, N. R. (1989) The conditions of conceptual change in the classroom. International Journal of Science Education, 11(5), 541-553.

HONDERICH, T. (Ed.). (1995) The Oxford Companion to Philosophy. Oxford: Oxford University Press.

HOYNINGEN-HUENE, P. (1993). Reconstructing Scientific Revolutions: Thomas S. Kuhn's Philosophy of Science. Chicago: The University of Chicago Press.

KEARNEY, M. (1984) World View. Novato:Chandler \& Sharp.

KUHN, T. S. [1970](1996). The Structure of Scientific Revolutions. Chicago: The University of Chicago Press.

LACEY, H. (1996) On relations between science and religion. Science \& Education, 5(2), 143-153. 
LAKATOS, I. [1970](1979) O falseamento e a metodologia dos programas de pesquisa. In: LAKATOS, I.; MUSGRAVE, A. (Eds.). A Crítica e o Crescimento do Conhecimento. São Paulo: Cultrix/EDUSP. pp. 109-243.

LAKATOS, I. \& MUSGRAVE, A. [1970](1979). A Crítica e o Crescimento do Conhecimento. São Paulo: Cultrix/EDUSP.

LÉVI-STRAUSS, C. [1966](1989). O Pensamento Selvagem. Campinas: Papirus.

LIMA-TAVARES, M. \& EL-HANI, C. N. (2001). Um olhar epistemológico sobre a transposição didática da teoria Gaia. Investigações em Ensino de Ciências, Vol. 6, n. 3.

MAHNER, M; BUNGE, M. (1996) Is religious education compatible with science education? Science \& Education, 5(2), 101-123.

MARQUES, J. G. W. (1995). Pescando Pescadores: Etnoecologia Abrangente no Baixo São Francisco Alagoano. São Paulo: NUPAUB.

MASTERMAN, M. [1970](1979). A natureza de um paradigma, LAKATOS, I. \& MUSGRAVE, A. A Crítica e o Crescimento do Conhecimento. São Paulo: Cultrix/EDUSP. pp. 72-108.

MATTHEWS, M. R. (1994a) Vino viejo en botellas nuevas: Un problema con la epistemología construtivista. Enseñanza de las Ciencias, 12(1), 79-88.

MATTHEWS, M. R. (1994b) Science Teaching: The Role of History and Philosophy of Science. New York: Routledge.

MATTHEWS, M. R. (1997) Introductory comments on philosophy and constructivism in science education. Science \& Education, 6(1-2), 15-28.

MCMULLIN, E. 1976. The fertility of theory and the unit for appraisal in science. Boston Studies in the Philosophy of Science, Vol. 39.

MEDIN, D. L. \& ATRAN, S. (1999). Folkbiology. Cambridge-MA: MIT Press.

MILLAR, R. (1989) Constructive criticisms. International Journal of Science Education, 11(5), 587-596.

MORTIMER, E. F. (1994) Evolução do Atomismo em Sala de Aula: Mudança de Perfis Conceituais. São Paulo: FE-USP. Tese de Doutorado.

MORTIMER, E. F. (1995) Conceptual change or conceptual profile change? Science \& Education, 4(3), 265-287.

MORTIMER, E. F. (1996) Construtivismo, mudança conceitual e ensino de ciências: para onde vamos? Investigações no Ensino de Ciências, 1(1), 20-39.

NIEDDERER, H.; GOLDBERG, F.; DUIT, R. (1991) Towards learning process studies: A review of the Workshop in Physics Learning. In: DUIT, R.; GOLDBERG, F.; NIEDDERER, H. (Eds.). Research in Physics Learning: Theoretical Issues and Empirical Studies. Kiel: Schmidt \& Klannig.

NOVAK, J. D. (1988) Constructivismo humano: Un consenso emergente. Enseñanza de las Ciencias 6(3), 213-223.

PEIRCE, C. S. (1955). Philosophical Writings of Peirce (edited by J. Buchler). New York: Dover.

PIAGET, J. ([1966]1987) O Nascimento da Inteligência na Criança. Rio de Janeiro: Guanabara.

PINTRICH, P. R.; MARX, R, W.; BOYLE, R. A. (1993) Beyond cold conceptual change: the role of motivational beliefs and classroom contextual factors in the process of conceptual change. Review of Educational Research, 63(2), 167-199. 
POLANYI, M. (1964) Personal Knowledge: Toward a Post-Critical Philosophy. New York: Harper and Row.

POSNER, G. J.; STRIKE, K. A.; HEWSON, P. W.; GERZOG, W. A. (1982) Accomodation of a scientific conception: toward a theory of conceptual change. Science Education, 66(2), 211-227.

PUTNAM, H. (1990) Realism with a Human Face. Cambridge-MA: Harvard University Press.

RESNICK, L. B. (1983) Mathematics and science learning: a new conception. Science, 220, 477-478.

RORTY, R. (1991) Objectivity, Relativism, and Truth: Philosophical Papers, Volume 1. Cambridge: Cambridge University Press.

SACKS, O. (1995) A new vision of the mind. In: CORNWELL, J. (Ed.). Nature's Imagination: the Frontiers of Scientific Vision. Oxford: Oxford University Press.

SCOTT, P. H.; ASOKO, H. M.; DRIVER, R. (1992). Teaching for conceptual change: A review of strategies. In: DUIT, R.; GOLDBERG, F.; NIEDDERER, H. (Eds.). Research in Physics Learning: Theoretical Issues and Empirical Studies. Kiel: Schmidt \& Klannig.

SETTLE, T. (1996) Applying scientific openmindedness to religion and science education. Science \& Education, 5(2), 125-141.

SEPÚLVEDA, C. (2002) A Relação entre Religião e Ciência na Trajetória de Formação Profissional de Alunos Protestantes da Licenciatura em Ciências Biológicas. Salvador: Mestrado em Ensino, Filosofia e História das Ciências. Dissertação de Mestrado (disponível em http://www.gphfecb.ufba.br/).

SEPÚLVEDA, C.; EL-HANI, C. N. (2001) Analisando as relações entre educação científica e educação religiosa. II. O uso de casos históricos de cientistas com crenças religiosas como ferramentas na formação de professores. Atas do III Encontro Nacional de Pesquisa em Educação em Ciências (ENPEC).

SOBER, E. (1994) Why not solipsism?, in: From a Biological Point of View: Essays in Evolutionary Philosophy. Cambridge: Cambridge University Press.

SOLOMON, J. (1994) The rise and fall of constructivism. Studies in Science Education, 23, 1-19.

STRIKE, K. A.; POSNER, G. J. (1992) A revisionist theory of conceptual change, in: DUSCHL, R.; HAMILTON, R. (Eds.). Philosophy of Science, Cognitive Psychology, and Educational Theory and Practice. Albany-NY: SUNY Press.

TOBIN, K. (Ed.). (1993) The Practice of Constructivism in Science and Mathematics Education. Washington: AAAS Press.

TOLEDO, V. M. (1990). La perspectiva etnoecologica: Cinco reflexiones acerca de las ciencias campesinas sobre la naturaleza com especial referencia a Mexico. Ciencias, $\mathrm{n}^{0}$ especial 4, 22-29.

TOLEDO, V. M. (1992). What is ethnoecology? Origins, scope and implications of a rising discipline. Etnoecologia, 1(1), 5-21.

VEYNE, P. (1984) Acreditavam os Gregos em seus Mitos?. São Paulo: Brasiliense.

WANDERSEE, J. H. (1993) The declared research interest of NARST members: An analysis of the 1992 NARST 'Directory of Members'. Journal of Research in Science Teaching, $30,319-320$. 
WHITE, T. R. \& GUNSTONE, R. F. (1989) Metalearning and conceptual change. International Journal of Science Education 11, 577-586.

WOLPERT, L. (1992) The Unnatural Nature of Science. London: Faber \& Faber.

WOOLNOUGH, B. (1996) On the fruitful compatibility of religious education and science. Science \& Education, 5(2), 175-183.

Data de apresentação:22-03-02

Data de aprovação:20-11-02 